\title{
Enhanced chlorhexidine skin penetration with eucalyptus oil
}

\author{
Tarja J Karpanen ${ }^{1,2}$, Barbara R Conway ${ }^{1,3^{*}}$, Tony Worthington ${ }^{1}$, Anthony C Hilton ${ }^{1}$, Tom SJ Elliott ${ }^{2}$, \\ Peter A Lambert ${ }^{1}$
}

\begin{abstract}
Background: Chlorhexidine digluconate $(\mathrm{CHG})$ is a widely used skin antiseptic, however it poorly penetrates the skin, limiting its efficacy against microorganisms residing beneath the surface layers of skin. The aim of the current study was to improve the delivery of chlorhexidine digluconate (CHG) when used as a skin antiseptic.

Method: Chlorhexidine was applied to the surface of donor skin and its penetration and retention under different conditions was evaluated. Skin penetration studies were performed on full-thickness donor human skin using a Franz diffusion cell system. Skin was exposed to $2 \%(\mathrm{~W} / \mathrm{V})$ CHG in various concentrations of eucalyptus oil (EO) and $70 \%(\mathrm{v} / \mathrm{v})$ isopropyl alcohol (IPA). The concentration of CHG $(\mu \mathrm{g} / \mathrm{mg}$ of skin) was determined to a skin depth of $1500 \mu \mathrm{m}$ by high performance liquid chromatography (HPLC).

Results: The $2 \%(\mathrm{~W} / \mathrm{v}) \mathrm{CHG}$ penetration into the lower layers of skin was significantly enhanced in the presence of EO. Ten percent ( $\mathrm{v} / \mathrm{V})$ EO in combination with $2 \%(\mathrm{w} / \mathrm{v}) \mathrm{CHG}$ in $70 \%(\mathrm{~V} / \mathrm{V})$ IPA significantly increased the amount of CHG which penetrated into the skin within 2 min.

Conclusion: The delivery of $\mathrm{CHG}$ into the epidermis and dermis can be enhanced by combination with EO, which in turn may improve biocide contact with additional microorganisms present in the skin, thereby enhancing antisepsis.
\end{abstract}

\section{Background}

Chlorhexidine ( $\mathrm{CHG})$ is a broad spectrum antimicrobial agent widely used for skin antisepsis prior to invasive procedures. However, the efficacy of CHG is reduced in the presence of organic matter and at low $\mathrm{pH}$ [1]. Furthermore, CHG, as with other antiseptic preparations exhibits restricted penetration through the skin; our previous studies demonstrate that $\mathrm{CHG}$ from aqueous and alcoholic [70\% (v/v) isopropyl alcohol (IPA)] solutions poorly penetrate the full thickness skin to the deeper skin layers $[2,3]$. This limits its efficacy against microorganisms residing in the lower layers of the epidermis and dermis, including hair follicles and sebaceous glands [2-6]. These persisting microorganisms, which include coagulase negative staphylococci, anaerobic bacteria such as Propionibacterium spp., and yeast Candida spp., may subsequently cause infection when the protective skin barrier is breached during

\footnotetext{
* Correspondence: b.r.conway@hud.ac.uk

${ }^{1}$ Life \& Health Sciences, Aston University, Aston Triangle, Birmingham, UK

Full list of author information is available at the end of the article
}

surgical procedures [7-10]. These microorganisms may also contaminate invasive medical devices such as intravascular catheters when they are passed through the skin, and thereby result in infection [11]. This residual source of microorganisms also offers an explanation for the relatively high incidence of surgical site infections which occurs despite the scrupulous use of currently available skin antiseptics. Indeed, an estimated $5 \%$ of patients who have undergone a surgical procedure develops a surgical site infection [12]. Novel strategies to enhance the penetration of antiseptic agents into the skin, thereby improving their efficacy against microorganisms located in the epidermis and dermis are therefore needed if these infections are to be prevented

Developments in the transdermal delivery of drugs offer a potential solution to improvement in the penetration of antiseptic agents into the skin. One such approach has been the application of essential oils, such as eucalyptus oil (EO), which contains terpenes [13]. Eucalyptus oil is an effective skin penetration enhancer and it contains 1,8-cineole, a monoterpene cyclic ether,
C Biomed Central

(c) 2010 Karpanen et al; licensee BioMed Central Ltd. This is an Open Access article distributed under the terms of the Creative Commons Attribution License (http://creativecommons.org/licenses/by/2.0), which permits unrestricted use, distribution, and reproduction in any medium, provided the original work is properly cited. 
which can enhance penetration of both lipophilic and hydrophilic compounds [14-17]. Terpenes, including 1,8-cineole, bind to the stratum corneum (SC) and are thought to enhance lipophilic drug penetration by increasing the partition coefficient and hydrophilic drug penetration by increasing the diffusion coefficient [18,19]. 1,8-cineole has been found to increase skin penetration by disrupting intercellular lipids in SC and to change SC membrane fluidity at the concentrations as low as $1 \%$ to $5 \%[16,17,19-22]$. Yamane et al. [17] however showed that the effect of lipid disruption was reversible and that 1,8-cineole did not result in lipid depletion from the SC.

Essential oils have also a broad spectrum of antimicrobial activity and this property has been harnessed in therapeutics, including skin cleansing (MRSA decolonisation) and treatment of necrotic ulcers [23-25]. Eucalyptus oil may therefore serve as a suitable candidate for enhancing the delivery of CHG into the skin, including hair follicles and sebaceous glands, where many microorganisms reside. The presence of EO may also enhance the antimicrobial activity of $\mathrm{CHG}$, as the combination has been shown to have synergistic antimicrobial activity against bacteria [26]. The aim of the current study was to evaluate the skin penetration of CHG and its retention at various depths of skin in the presence of EO.

\section{Methods}

\section{Materials}

Sodium heptane sulphonate, diethylamine (both highperformance liquid chromatography [HPLC] grade), phosphate buffered saline (PBS) tablets, aqueous $20 \%$ (w/v) CHG, eucalyptus oil (EO) (containing 82.9\% cineole) and isopropyl alcohol (IPA) were purchased from Sigma-Aldrich (Dorset, UK). Phosphate buffered saline (Sigma-Aldrich, Dorset, UK) was reconstituted from tablets according to manufacturers' instructions. Methanol and glacial acetic acid (all HPLC grade) were purchased from Fisher Scientific (Leicestershire, UK).

\section{Skin samples}

Full thickness human skin samples were obtained from three patients undergoing breast reduction surgery and who consented their excised skin for ethically approved research study. The donor skin was frozen on the day of excision and stored at $-70^{\circ} \mathrm{C}$ until required. Full ethical committee approval was obtained prior to this study from South Birmingham Research Ethics Committee.

\section{Quantification of CHG}

High-performance liquid chromatography was used to measure CHG in the skin samples obtained during the penetration studies. The analyses were performed with an Agilent 1200 series HPLC system (Agilent Technologies,
UK). The samples were run at a flow rate of $1.2 \mathrm{~mL} / \mathrm{min}$ at room temperature through a reverse phase chromatography column [CPS-2 Hypersil; dimension $150 \times 4.6 \mathrm{~mm}$, $5 \mu \mathrm{m}$ particle size (Thermo Electron Corporation, UK)] with ultraviolet detection at a wavelength of $254 \mathrm{~nm}$. The isocratic mobile phase consisted of a methanol: water mixture $(75: 25)$ with $0.005 \mathrm{M}$ sodium heptane sulphonate and $0.1 \%(\mathrm{v} / \mathrm{v})$ diethylamine adjusted to $\mathrm{pH} 4.0$ with glacial acetic acid. The method for CHG quantification by HPLC was validated and the levels of detection (LOD) and quantification (LOQ) were determined as previously described [2].

\section{CHG skin penetration profile studies}

Skin penetration studies were performed with vertical Franz diffusion cells as previously described [2]. In brief, skin samples were mounted onto Franz diffusion cells with the stratum corneum (SC) uppermost facing the donor compartment. The receptor compartment was filled with $29 \mathrm{~mL}$ of PBS maintained at $37^{\circ} \mathrm{C}$ ). The skin was left to equilibrate for $30 \mathrm{~min}$ to reach the temperature of $32^{\circ} \mathrm{C}$ before application of the test solution (the surface area of skin exposed to the test compound was $3.14 \mathrm{~cm} 2$ ).

Twenty percent (w/v) aqueous CHG was diluted with distilled water, IPA and EO to obtain the final concentrations of $2 \%(\mathrm{w} / \mathrm{v})$ CHG with $5 \%, 10 \%, 20 \%$ and $50 \%(\mathrm{v} / \mathrm{v})$ EO and $10 \%(\mathrm{v} / \mathrm{v})$ EO with $2 \%(\mathrm{w} / \mathrm{v})$ CHG in $70 \%(\mathrm{v} / \mathrm{v})$ IPA. Tween $80[0.1 \%(\mathrm{v} / \mathrm{v})]$ was added to the test solutions to enhance EO solubility in the vehicle. One $\mathrm{mL}$ of each test solution was spread over a separate skin surface in the donor compartment. Following a $2 \mathrm{~min}, 30 \mathrm{~min}$ and $24 \mathrm{~h}$ exposure, skin samples were removed, washed with PBS and sprayed with a cryospray (Bright Instruments, Cambridgeshire, UK) and frozen at $-20^{\circ} \mathrm{C}$. Punch biopsies (7 $\mathrm{mm}$ in diameter) were then cut from each frozen sample in triplicate and the samples were sectioned horizontally with a cryotome (Bright Instruments) into $20 \mu \mathrm{m}$ sections (from the surface to a depth of $600 \mu \mathrm{m}$ ) and $30 \mu \mathrm{m}$ sections (from depths of 600 to $1500 \mu \mathrm{m}$ ).

Chlorhexidine was extracted from the skin by mobile phase solution and analysed by HPLC (CHG extraction was validated prior to the study as described previously) [2]. The amounts of $\mathrm{CHG}$ were calculated as $\mu \mathrm{g}$ per $\mathrm{mg}$ of skin. Control skin (with no added CHG treatment) was analysed parallel to the test samples. The assay was performed in triplicate.

\section{Determination of CHG permeation through the full thickness skin}

During the skin permeation studies $1 \mathrm{~mL}$ of receptor fluid was removed every $30 \mathrm{~min}$ for $2 \mathrm{~h}$, every hour between 2 to $6 \mathrm{~h}$ and at $8 \mathrm{~h}, 12 \mathrm{~h}$ and $24 \mathrm{~h}$. Fluid removed from the receptor compartment was immediately replaced with an equal volume of fresh PBS solution. All samples were 
filtered and analysed by HPLC. The assays were performed in triplicate.

\section{Statistical analysis}

The data obtained were analysed by a student $\mathrm{t}$-test with INSTAT3 software (Graph pad software version 3.06) with a $\mathrm{p}<0.05$ level of significance.

\section{Results}

\section{Chlorhexidine skin penetration following exposure to} CHG in combination with $50 \%(v / v)$ EO

Combining 2\% (w/v) CHG with 50\% (v/v) EO enhanced penetration of CHG into the lower layers of skin within $2 \mathrm{~min}$; the CHG concentrations achieved at depths of 300- $1500 \mu \mathrm{m}$ were between $0.019-0.043 \mu \mathrm{g}$ per $\mathrm{mg}$ tissue (Figure 1). After $30 \mathrm{~min}$ the concentration of CHG in the upper $100 \mu \mathrm{m}$, following application of $2 \%$ (w/v) CHG with 50\% (v/v) EO, was $0.398(+/-0.076) \mu \mathrm{g}$ per mg tissue (Figure 1).

\section{CHG skin penetration following exposure to CHG in} various concentrations of EO

The effect of different EO concentrations on CHG penetration into the skin was evaluated over a 24 -h period.
Five percent (v/v) EO facilitated greater CHG skin penetration to the deeper layers of the skin (below $300 \mu \mathrm{m}$ ) and $10 \%(\mathrm{v} / \mathrm{v})$ EO enhanced CHG skin penetration in the upper $900 \mu \mathrm{m}$. There were no significant differences in CHG concentration achieved in the skin following application of 2\% (w/v) CHG with 10\% (v/v) EO or 20\% (v/v) EO (Figure 2).

\section{Chlorhexidine skin penetration with alcohol and EO}

The optimum EO concentration, which enhanced CHG penetration into the full thickness human skin, was further evaluated in combination with $2 \%(\mathrm{w} / \mathrm{v}) \mathrm{CHG}$ in $70 \%(\mathrm{v} / \mathrm{v})$ IPA. Ten percent $(\mathrm{v} / \mathrm{v})$ EO in combination with $2 \%(\mathrm{w} / \mathrm{v})$ CHG in $70 \%(\mathrm{v} / \mathrm{v})$ IPA demonstrated enhanced CHG skin penetration after a 2-min and 30min exposure on the skin (Figure 3).

\section{CHG penetration through the full thickness skin}

Chlorhexidine was not detected in the receptor compartment (LOD $0.0157 \mu \mathrm{g} / \mathrm{mL}$ ) during the 24 h skin permeation study under any conditions when using full thickness human skin (epidermis and dermis) from two of three different donors. Less than $0.0016 \%$ of the applied dose of $\mathrm{CHG}$ was detected during the skin

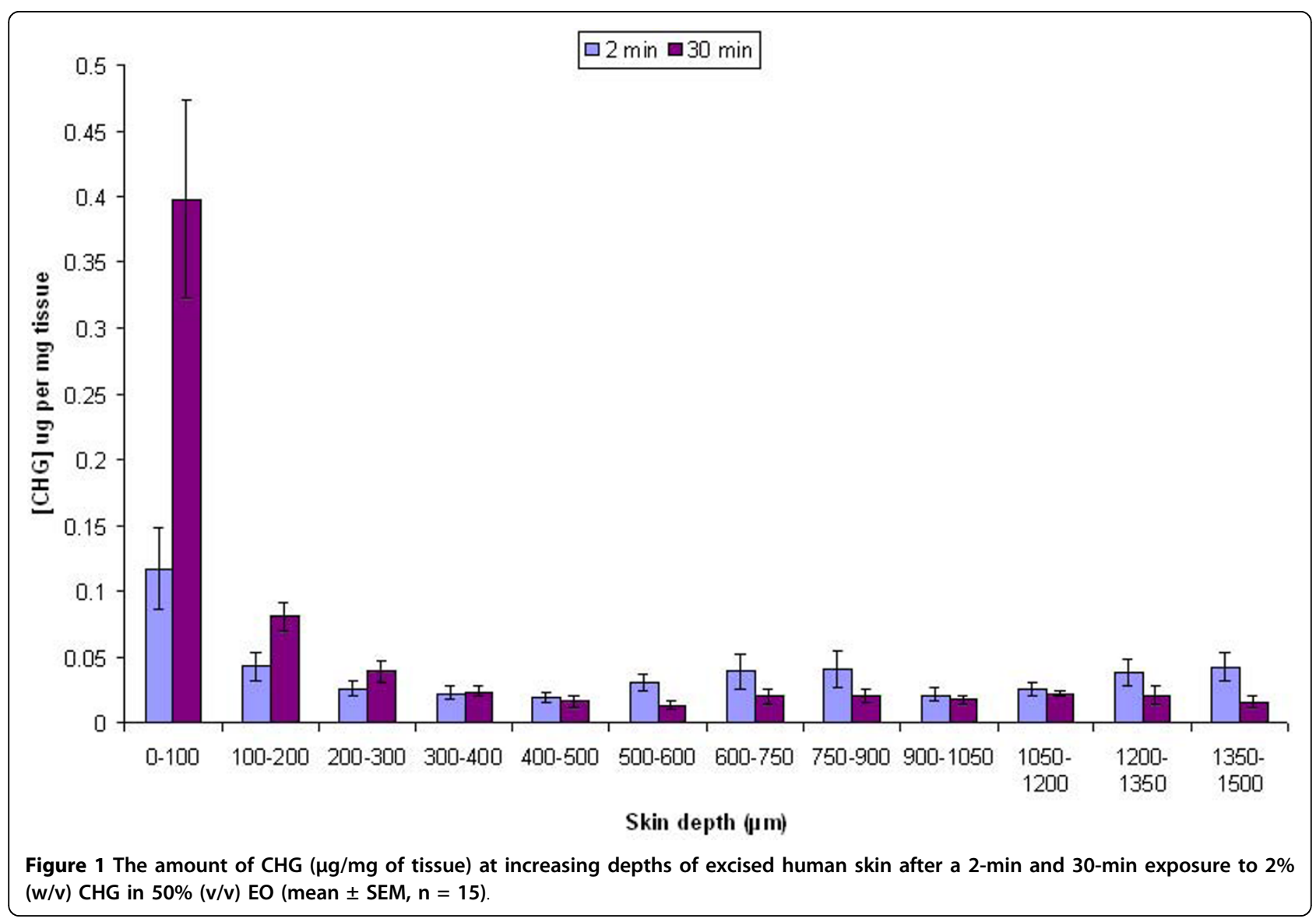



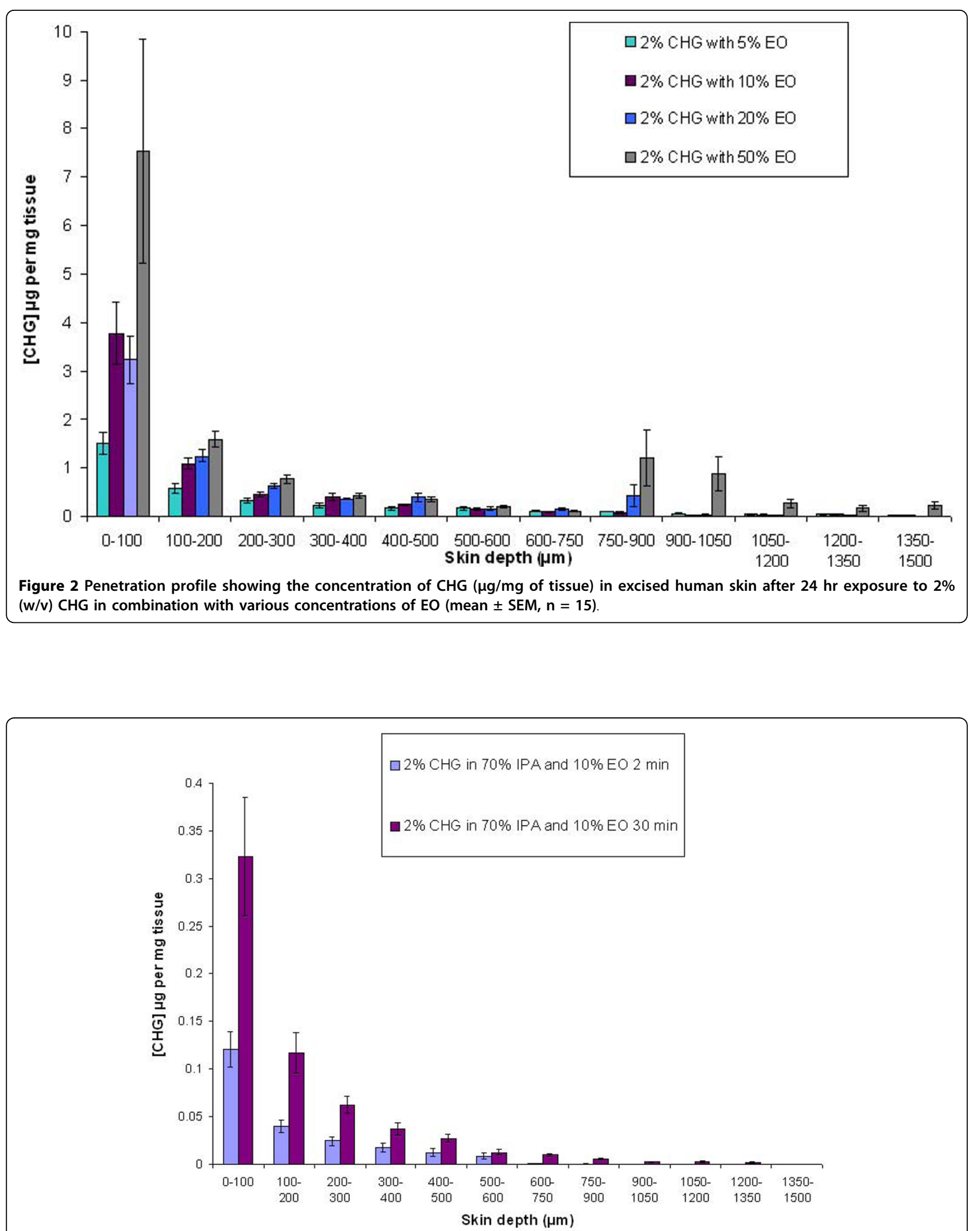

Figure 3 The amount of CHG ( $\mu \mathrm{g} / \mathrm{mg}$ of tissue) at increasing depths of excised human skin after a 2-min ( $=10)$ and 30-min exposure $(n=15)$ to $2 \%(w / v)$ CHG in $70 \%(v / v)$ IPA and $10 \%(v / v)$ EO (mean \pm SEM). 
permeation studies on the third donor skin $(<0.32 \mu \mathrm{g} /$ $\mathrm{mL}$ ) following 24-h exposure to $2 \%$ (w/v) CHG with $50 \%(\mathrm{v} / \mathrm{v}) \mathrm{EO}$.

\section{Discussion}

In the current study penetration of CHG into the lower layers of the epidermis and dermis was enhanced when applied in combination with EO. This enhanced penetration has the potential for improving skin antisepsis in clinical practice by increasing the concentration of $\mathrm{CHG}$ beneath the surface layers of skin where microorganisms can reside. Indeed, the concentration of $\mathrm{CHG}$ within the upper $100 \mu \mathrm{m}$ of skin was increased from $0.023(+/-$ $0.007) \mu \mathrm{g} / \mathrm{mg}$ of tissue (as presented in our previous study [3]) to $0.121(+/-0.019) \mu \mathrm{g} / \mathrm{mg}$ of tissue after 2 min application of $2 \%(\mathrm{w} / \mathrm{v})$ CHG in $70 \%(\mathrm{v} / \mathrm{v})$ IPA and $10 \%$ (v/v) EO compared to CHG/IPA alone. Assuming that $1 \mathrm{~g}$ of tissue is equal to $1 \mathrm{~mL}$, these concentrations of CHG achieved are higher than the minimum bactericidal concentration against many skin microorganisms such as Staphylococcus epidermidis [26]. However, a microbial reservoir can reside in the deeper layers of the skin (and sebaceous glands) following skin antisepsis [4], which may contribute to high number of infections associated with invasive procedures such as surgery or insertion of intravascular catheters. Improved skin delivery of antiseptic agents may therefore enhance skin antisepsis and reduce the risk of infection associated with the invasive procedures and also intravascular catheters. The use of $2 \%(\mathrm{w} / \mathrm{v}) \mathrm{CHG}$ in EO may therefore reduce the likelihood of re-seeding of microorganisms onto the skin surface following skin antisepsis, thereby further reducing the risk of infection.

Two percent (w/v) CHG in $70 \%(\mathrm{v} / \mathrm{v})$ IPA is a recommended antiseptic agent for central venous catheter (CVC) insertion and CVC site care [27]. The skin penetration of CHG following application of $2 \%(w / v)$ CHG in $70 \%$ (v/v) IPA onto skin was however limited [3]. Chlorhexidine in alcohol has been shown to have superior antimicrobial activity compared to $2 \%(\mathrm{w} / \mathrm{v})$ aqueous $\mathrm{CHG}$, however their efficacy in reducing intravascular catheter related infections and catheter colonisation are comparable [28-30]. Alcohol, at high concentrations, has a rapid and broad spectrum of antimicrobial activity, but it has been shown to extract SC lipids and dehydrate SC proteins, therefore increasing the SC permeation barrier [31-34]. However, combining 10\% (v/v) EO with 2\% (w/v) CHG in $70 \%(v / v)$ IPA significantly enhanced CHG skin penetration compared to CHG/IPA alone. Similar previous studies on terpenes in combination with ethanol have shown increased skin permeation of diclofenac sodium [35]. The application of CHG in alcohol and EO seems to offer a solution for enhancing CHG skin penetration but still retaining its skin surface antiseptic activity.
Eucalyptus oil and chlorhexidine are currently used in various pharmaceutical preparations, which are applied to the skin and mucous membranes. These compounds are regarded as safe with few reported adverse reactions. Side effects of CHG have included contact dermatitis and rarely hypersensitivity and anaphylaxis. In comparison, EO adverse reactions are less well known, however $7 \%$ EO has been used on necrotic neck ulcers (in combination with other oils) without adverse reactions [25]. Regarding systemic reactions, in this current study CHG was only detected at negligible levels in the receptor compartment suggesting that $\mathrm{CHG}$ does not permeate through the full skin thickness, and is retained within the tissue. This property reduces the risk of systemic adverse reaction. Indeed, these results further support previous research on another CHG based compound, chlorhexidine phosphanilate, which did not permeate through the full thickness of skin [36]. Furthermore, other studies have shown that cineole, which is the predominant terpene in $\mathrm{EO}$, binds to $\mathrm{SC}$ and is retained in the skin and does not permeate through the skin in in vitro assays [18,19,37]. It would therefore appear that both CHG and EO have a minimal risk of stimulating systemic reactions as they poorly permeate the whole skin. Further clinical studies on this are however required to substantiate this.

\section{Conclusions}

In conclusion, the current study demonstrates that $2 \%$ (w/v) CHG penetration into the deeper layers of skin was significantly enhanced with EO compared to CHG in aqueous solutions or in $70 \%$ (v/v) IPA. Furthermore, $2 \%(\mathrm{w} / \mathrm{v}) \mathrm{CHG}$ in combination with $70 \%(\mathrm{v} / \mathrm{v})$ IPA and $10 \%(\mathrm{v} / \mathrm{v})$ EO significantly increased the amount of CHG in the skin within 2 min compared to CHG/IPA. These exciting results lay the foundation for further research within this area with a view to potentially adopting alternative strategies for enhanced skin antisepsis in clinical practice. Further studies need to be undertaken to determine the skin tolerance of EO and the clinical efficacy of CHG in combination with EO in reducing the number of infections associated with invasive procedures such as insertion of intravascular catheters.

\section{Author details}

${ }^{1}$ Life \& Health Sciences, Aston University, Aston Triangle, Birmingham, UK. ${ }^{2}$ Department of Clinical Microbiology, University Hospitals Birmingham NHS Foundation Trust, Queen Elizabeth Hospital, Edgbaston, UK. ${ }^{3}$ Pharmacy and Pharmaceutical Sciences, University of Huddersfield, Huddersfield, UK.

\section{Authors' contributions}

TJK, TW, BRC and PAL have participated in the design, analysis of the data and drafting this manuscript. TJK performed the skin permeation studies. $\mathrm{ACH}$ contributed to the statistical analysis of the data and drafting this 
manuscript. TSJE contributed to the analysis of the data and drafting this manuscript. All authors have read and approved the final manuscript.

\section{Competing interests}

The synergistic antimicrobial activity of $\mathrm{CHG}$ and $\mathrm{EO}$ and the enhanced skin permeation of $\mathrm{CHG}$ in combination with $\mathrm{EO}$ holds an international patent (PCT/GB2008/002832). Other authors have no competing interests.

Received: 24 March 2010 Accepted: 22 September 2010

Published: 22 September 2010

\section{References}

1. McDonnell G, Russell AD: Antiseptics and disinfectants: activity, action, and resistance. Clin Microbiol Rev 1999, 12(1):147-179.

2. Karpanen TJ, Worthington T, Conway BR, Hilton AC, Elliott TS, Lambert PA: Penetration of chlorhexidine into human skin. Antimicrob Agents Chemother 2008, 52:3633-3636.

3. Karpanen TJ, Worthington T, Conway BR, Hilton AC, Elliott TS, Lambert PA: Permeation of chlorhexidine from alcoholic and aqueous solutions within excised human skin. Antimicrob Agents Chemother 2009, 53(4):1717-1719.

4. Hendley JO, Ashe KM: Effect of Topical Antimicrobial Treatment on Aerobic Bacteria in the Stratum Corneum of Human Skin. Antimicrobial Agents and Chemotherapy 1991, 35(4):627-631.

5. Hendley JO, Ashe KM: Eradication of Resident Bacteria of Normal Human Skin by Antimicrobial Ointment. Antimicrobial Agents and Chemotherapy 2003, 47(6):1988-1990.

6. Lafforgue C, Carret L, Falson F, Reverdy ME, Freney J: Percutaneous absorption of a chlorhexidine digluconate solution. International Journal of Pharmaceutics 1997, 147:243-246.

7. Brown E, Wenzel RP, Hendley JO: Exploration of the microbial anatomy of normal human skin by using plasmid profiles of coagulase-negative staphylococci: search for the reservoir of resident skin flora. Journal of Infectious Disease 1989, 160(4):644-650.

8. Elsner P: Antimicrobials and the skin physiological and pathological flora. Curr Probl Dermatol 2006, 33:35-41.

9. Leeming JP, Holland KT, Cunliffe WJ: The microbial ecology of pilosebaceous units isolated from human skin. Journal of General Microbiology 1984, 130(4):803-807.

10. Nielsen ML, Raahave D, Stage JG, Justesen T: Anaerobic and aerobic skin bacteria before and after skin-disinfection with chlorhexidine: an experimental study in volunteers. J Clin Pathol 1975, 28(10):793-797.

11. Elliott TSJ, Moss HA, Tebbs SE, Wilson IC, Bonser RS, Graham TR, Burke LP, Faroqui $\mathrm{MH}$ : Novel approach to investigate a source of microbial contamination of central venous catheters. European Journal of Clinical Microbiology and Infectious Diseases 1997, 16(3):210-213.

12. Smyth ET, Mcllvenny G, Enstone JE, Emmerson AM, Humphreys $H_{\text {, }}$ Fitzpatrick F, Davies E, Newcombe RG, Spencer RC: Four country healthcare associated infection prevalence survey 2006: overview of the results. J Hosp Infect 2008, 69(3):230-248.

13. Aqil M, Ahad A, Sultana Y, Ali A: Status of terpenes as skin penetration enhancers. Drug Discovery Today 2007, 12(23-24):1061-1067.

14. Biruss B, Kahliq $H$, Valenta C: Evaluation of an eucalyptus oil containing topical drug delivery system for selected steroid hormones. International Journal of Pharmaceutics 2007, 328:142-151.

15. Femenia-Font A, Balaguer-Fernandez C, Merino V, Rodilla V, LopezCastellano A: Effect of chemical enhancers on the in vitro percutaneous absorption of sumatriptan succinate. European Journal of Pharmaceutics and Biopharmaceutics 2005, 61:50-55.

16. Narishetty STK, Panchagnula R: Effect of L-menthol and 1,8-cineole on phase behavior and molecular organization of SC lipids and skin permeation of zidovudine. J Control Release 2005, 102:59-70.

17. Yamane MA, Williams AC, Barry BW: Effects of terpenes and oleic acid as skin penetration enhancers towards 5 -fluorouracil as assessed with time; permeation, partitioning and differential scanning calorimetry. International Journal of Pharmaceutics 1995, 116:237-251.

18. Cal K, Janicki S, Sznitowska M: In vitro studies on penetration of terpenes from matrix-type transdermal systems through human skin. International Journal of Pharmaceutics 2001, 224(1-2):81-88.

19. Cornwell PA, Barry BW, Bouwstra JA, Gooris GS: Modes of action of terpene penetration enhancers in human skin; differential scanning calorimetry, small-angle X-ray diffraction and enhancer uptake studies. International Journal of Pharmaceutics 1996, 127:9-26.

20. Anjos JL, Neto Dde S, Alonso A: Effects of 1,8-cineole on the dynamics of lipids and proteins of stratum corneum. Int J Pharm 2007, 345(1-2):81-87.

21. Gao S, Singh J: Meachanism of trandermal transport of 5-fluorouracil by terpenes: carvone, 1,8-cineole and thymol. Int J Pharm 1997, 154:67-77.

22. Williams AC, Edwards HGM, Lawson EE, Barry BW: Molecular interactions between the penetration enhancer 1,8-cineole and human skin. Journal of Raman Spectroscopy 2006, 37:361-366.

23. Sherry E, Sivananthan S, Warnke PH, Eslick GD: Topical phytochemicals used to salvage the gangrenous lower limbs of type 1 diabetic patients. Diabetes Research and Clinical Practice 2003, 62(1):65-66.

24. Warnke PH, Becker ST, Podschun R, Sivananthan S, Springer IN, Russo PA, Wiltfang J, Fickenscher $\mathrm{H}$, Sherry E: The battle against multi-resistant strains: Renaissance of antimicrobial essential oils as a promising force to fight hospital-acquired infections. J Craniomaxillofac Surg 2009, 37(7):392-397.

25. Warnke PH, Sherry E, Russo PAJ, Acil Y, Wiltfang J, Sivananthan S, Sprengel M, Roldan JC, Schubert S, Bredee JP, Springer ING: Antibacterial essential oils in malodorous cancer patients: Clinical observations in 30 patients. Phytomedicine 2006, 13(7):463-467.

26. Karpanen TJ, Worthington T, Hendry ER, Conway BR, Lambert PA: Antimicrobial efficacy of chlorhexidine digluconate alone and in combination with eucalyptus oil, tea tree oil and thymol against planktonic and biofilm cultures of Staphylococcus epidermidis. J Antimicrob Chemother 2008, 62(5):1031-1036.

27. Pratt RJ, Pellowe CM, Wilson JA, Loveday HP, Harper PJ, Jones SR, McDougall C, Wilcox MH: epic2: National evidence-based guidelines for preventing healthcare-associated infections in NHS hospitals in England. $J$ Hosp Infect 2007, 65(Suppl 1):S1-64.

28. Adams D, Quayum M, Worthington T, Lambert P, Elliott T: Evaluation of a $2 \%$ chlorhexidine gluconate in $70 \%$ isopropyl alcohol skin disinfectant. J Hosp Infect 2005, 61(4):287-290.

29. Hibbard JS, Mulberry GK, Brady AR: A clinical study comparing the skin antisepsis and safety of ChloraPrep, 70\% isopropyl alcohol, and 2\% aqueous chlorhexidine. J Infus Nurs 2002, 25(4):244-249.

30. Valles J, Fernandez I, Alcaraz D, Chacon E, Cazorla A, Canals M, Mariscal D, Fontanals D, Moron A: Prospective randomized trial of 3 antiseptic solutions for prevention of catheter colonization in an intensive care unit for adult patients. Infect Control Hosp Epidemiol 2008, 29(9):847-853.

31. Adams DH: An evaluation of three strategies to reduce device related infections associated with hypodermic needles and peripheral vascular catheters. Birmingham: Aston University 2006.

32. Amini T: Chemical and physical methods of enhancing the percutaneous absorption of antimicrobial agents. Birmingham: Aston University 2001

33. dos Anjos JL, de Sousa Neto D, Alonso A: Effects of ethanol/I-menthol on the dynamics and partitioning of spin-labeled lipids in the stratum corneum. Eur J Pharm Biopharm 2007, 67(2):406-412.

34. Van der Merwe D, Riviere JE: Comparative studies on the effects of water, ethanol and water/ethanol mixtures on chemical partitioning into porcine stratum corneum and silastic membrane. Toxicol In Vitro 2005, 19(1):69-77.

35. Obata Y, Takayama K, Machida Y, Nagai T: Combined effect of cyclic monoterpenes and ethanol on percutaneous absorption of diclofenac sodium. Drug Des Discov 1991, 8(2):137-144.

36. Wang JC, Williams RR, Wang L, Loder J: In vitro skin permeation and bioassay of chlorhexidine phosphanilate, a new antimicrobial agent. Pharm Res 1990, 7(10):995-1002.

37. Cal K, Kupiec K, Sznitowska M: Effect of physicochemical properties of cyclic terpenes on their ex vivo skin absorption and elimination kinetics. Journal of Dermatological Science 2006, 41(2):137-142.

\section{Pre-publication history}

The pre-publication history for this paper can be accessed here: http://www.biomedcentral.com/1471-2334/10/278/prepub

doi:10.1186/1471-2334-10-278

Cite this article as: Karpanen et al:: Enhanced chlorhexidine skin penetration with eucalyptus oil. BMC Infectious Diseases 2010 10:278. 